\title{
Preserving Skin Integrity with Chronic Device Use in Diabetes
}

\author{
Laurel H. Messer, RN, MPH, CDE, Cari Berget, RN, MPH, CDE, \\ Christie Beatson, RD, MS, CDE, Sarit Polsky, MD, and Gregory P. Forlenza, MD
}

\begin{abstract}
Skin integrity and diabetes device placement are ongoing concerns for people with diabetes who utilize continuous glucose monitors (CGMs) and continuous subcutaneous insulin infusion pumps. This is especially significant for individuals with skin sensitivities, pediatric patients, and those who use devices chronically. Dermatological complications are often cited as a barrier to device use and a reason for device discontinuation. Furthermore, it is a frequent topic of discussion in diabetes follow-up visits, although little evidence-based literature exists to guide providers in managing skin integrity issues. The purpose of this article is to review current literature related to the prevalence of dermatological issues with insulin pumps and CGM, discuss published solutions to skin irritation, and to share the consolidated experience of our large academic diabetes clinic to address placement, prophylactic skin care, adhesives, removal, and skin healing with diabetes device use. Recommendations for targeted studies, increased surveillance, and development of new adhesive compounds are suggested to reduce the burden of device wear for management of diabetes.
\end{abstract}

Keywords: Skin care, Hypersensitivity, Dermatitis, Diabetes, CGM, CSII.

\section{Introduction}

C

URRENT CARE FOR TyPe 1 Diabetes (T1D) frequently includes use of a Continuous Glucose Monitor (CGM) for glucose self-monitoring and/or Continuous Subcutaneous Insulin Infusion (CSII) therapy, also known as an insulin pump, for insulin administration. ${ }^{1}$ Concomitant use of CGM and CSII, as either sensor-augmented pump or hybrid closedloop artificial pancreas therapy, is also becoming more commonplace. Both devices involve a small filament or cannula being inserted under the skin and secured with an external adhesive patch. The adhesive footprint on the skin varies in size, with tubed infusion sets offering the smallest surface area, and CGMs and patch pumps requiring a larger adhesive body. CGM sensors are approved to be worn on the skin for 7-14 days before replacement, while CSII infusion sets should be replaced every 2-4 days. ${ }^{2,3}$

Use of CSII has been associated with a $0.5 \%$ lower hemoglobin A1c (HbA1c) than use of multiple daily injection (MDI) therapy, and use of a CGM has been associated with a $0.9 \%$ lower HbA1c than self-monitoring of blood glucose (SMBG) alone. ${ }^{4}$ According to data from large multinational pediatric registries, $\sim 41 \%-47 \%$ of patients use CSII. ${ }^{5} \mathrm{~A}$ recent survey of T1D Exchange pediatric and adult participants revealed that almost $40 \%$ of patients surveyed are using CGM as part of their management plan with a growing percentage of MDI patients also incorporating CGM. ${ }^{6}$ With the recent approvals of nonadjunctive use of the Dexcom G5 and G6 CGMs (for insulin dosing without concurrent SMBG testing) and approval of the factory-calibrated Dexcom G6 CGM and flash glucose monitor Abbott Freestyle Libre, it is likely that use of these technologies will grow in the next several years. ${ }^{7-9}$ With the increasing use of these devices, dermatological concerns are becoming more common in people with diabetes. Skin issues are frequently reported to endocrinologists and diabetes educators in clinical practice, and are a persistent topic in diabetes support groups and social media websites. ${ }^{10}$ Few resources are available, however, to guide clinicians on how to comprehensively assess, prevent, and treat skin conditions associated with diabetes device usage.

The purpose of this article is to review relevant dermatological concerns related to diabetes devices, and recommend practical guidelines for optimal skin management, with primary emphasis on location/placement, adhesion, preventing skin reactions, and healing existing skin reactions.

Barbara Davis Center for Childhood Diabetes, University of Colorado Denver, Aurora, Colorado. 


\section{Dermatological Concerns with Diabetes Devices}

\section{Skin reactions in the diabetes literature}

Although use of CSII and CGM can lead to similar skin integrity and adhesive problems, the literature bodies are largely discrete, as routine CSII use preceded CGM use by 20 years. A recent study in 143 pediatric patients showed that $90 \%$ of individuals using CSII $>4$ months experienced dermatological complications from insulin infusion sets (IIS), including pruritus $(77 \%)$, wounds $(50 \%)$, and nonspecific eczema (46\%). ${ }^{11}$ It also found that individuals with a history of atopic disease were 3.7 times more likely to experience dermatological complications compared to those without an atopic history $(P<0.01)$. Barrier cream use was also associated with higher risk for skin reactions (OR 7.3, $P<0.01$ ), although this may be due to patient attempts to reduce reactions and not the cause of reactivity. ${ }^{11}$ Another pediatric study reported scars $<3 \mathrm{~mm}$ as the most common dermatologic complication from IIS (94\%), followed by erythema (66\%), lipohypertrophy (LH) (44\%), subcutaneous nodules (erythematous $42 \%$ and nonerythematous $20 \%$ ), scars $\geq 3 \mathrm{~mm}$ (12\%), and less than $10 \%$ each from epidermal abrasions, hyperpigmentation, lipoatrophy, and bruising. ${ }^{12}$ Binder et al. conducted a cross-sectional observational study with CSII users (3-20 years old) and found that $43 \%$ experienced scarring (24\%), LH (20\%), eczema-like lesions (11\%), pigmentation changes $(6 \%)$, and lipoatrophy $(6 \%){ }^{13}$ The study also showed that steel catheter use was not associated with a lower prevalence of skin complications compared to Teflon sets $(37 \%$ steel vs. $53 \%$ Teflon, $P=0.39) .{ }^{13} \mathrm{LH}$ has further been reported as one of the most common issue associated with CSII use. $^{14}$

CGM use has also been shown to cause dermatological issues. The earliest indication of CGM adhesive irritation and hypersensitivity appeared in the literature in $2007,{ }^{15}$ with the DirecNet study group subsequently reporting skin irritation and rashes in a pediatric study popluatuon. ${ }^{16}$ This was more commonly found in individuals who had never used an insulin pump or CGM before. ${ }^{17}$ Ives et al. reported similar findings in a clinical pediatric population using CGM, reporting skin irritation and poor adhesion exacerbated by sweating and activity. ${ }^{18}$ A more recent randomized controlled trial of CGM in pregnancy reported that $48 \%$ of pregnant women and $44 \%$ of women planning pregnancy experienced adverse skin reactions with CGM, including erythema (31\%), chronic dry skin (11\%), and hyperpigmentation (7\%), but "other" was the reason for $23 \%$ of the total cohort's skin reactions. ${ }^{19}$ Of particular concern, $18 \%$ of participants cited skin irritation/ pain/discomfort as the reason for discontinuing CGM use. ${ }^{19}$ Finally, a recent report from 83 pediatric patients using CGM showed $80 \%$ experiencing skin issues, including pruritus $(70 \%)$, eczema $(46 \%)$, and wounds $(33 \%) .{ }^{11}$ There was no difference in risk for dermatological issues by age or history of atopy, although individuals who used CGM for less than 1 year did report fewer complications. ${ }^{11}$

Few reports compare skin complications across devices. CSII and CGM have slightly different complications due to unique concerns with insulin infusion (e.g., LH) and the longer duration of CGM sensors. In both CGM and CSII use, dermatological complications typically appear within 4 to 6 months of initiation, although pediatric subjects in one recent study reported the CGM skin issues to be more problematic than IIS skin issues. ${ }^{11}$ This same study further reported more dermatological issues with the Medtronic Enlite and Dexcom G5 sensor compared to Freestyle Libre. ${ }^{11}$ Since the Libre has not been on the market as long as other sensors, there is less data on its use. During the IMPACT trial using the Libre in 328 adults, ${ }^{21}$ there were 13 cutaneous adverse events in 10 participants, with 6 being classified as severe. ${ }^{22}$ Since completion of the trial, Abbott made changes to the commercial Libre device to improve breathability of the skin and reduce the occurrence of trapped moisture between the sensor and skin. $^{24}$

\section{Etiology of dermatological concerns}

As the literature has shown, CGM and CSII device usage can lead to skin injury and irritation (hypersensitivity reactions, contact dermatitis), scarring, and lipodystrophy. Hypersensitivity reactions are typically classified as one of four types. $^{25}$ Type 1 hypersensitivity is termed immediate type hypersensitivity, is IgE mediated, and is the form most common in atopic-type skin reactions. Reactions typically occur within minutes. Type 2 hypersensitivity (cytotoxic) and type 3 hypersensitivity (immune complex) are not typical to diabetes device wear, and are not covered in this study. Type 4 hypersensitivity is termed delayed-type or cellmediated hypersensitivity, and is the most common form of hypersensitivity reaction. It is T-cell mediated, and occurs in response to sensitization to the offending agent in susceptible individuals. Reactions typically take a long period of exposure to induce initially, but may occur more rapidly after repeated exposure due to reactivation of memory Th1 cells. These reactions may occur in response to chemicals in CGM and IIS adhesives.

Contact dermatitis is a broader term describing both type 4 hypersensitivity reaction described above (also known as allergic contact dermatitis), as well as irritant contact dermatitis. ${ }^{26,27}$ Irritant contact dermatitis occurs as a result of direct damage to the skin by chemical or physical agents resulting in a nonimmune inflammatory reaction. Irritant and allergic contact dermatitis are not mutually exclusive, however, destruction of the skin barrier by irritant contact dermatitis may play a role in increasing antigenic exposure and exacerbate or accelerate allergic contact dermatitis. ${ }^{10}$ The type of adhesive used in a device also plays a key role in development of allergic contact dermatitis. While the exact composition and preparation of adhesives used by various manufacturers remain a trade secret, most contain acrylate monomers, which are known to be a potent source of contact dermatitis. ${ }^{10,20}$ There is one published case report detailing sensitization to ethyl cyanoacrylates in a Dexcom G4 sensor adhesive in a 2-year-old girl. ${ }^{20}$ Another study reported on 15 patients with allergic contact dermatitis caused by the Freestyle Libre, and patch testing revealed that all patients had been sensitized to isobornyl acrylate in the adhesive. ${ }^{23}$

Scarring is another dermatological complication from CGM and IIS and appears to be more common with IIS. Scarring manifests as small hypo- or hyperpigmented lesions of fibrous tissue. ${ }^{12,28}$ Although it is unclear whether scarring affects sensor accuracy or insulin absorption, it may disrupt the insertion process of sensors or cannulas, and scarred areas should therefore be avoided when selecting new insertion sites. 
Finally, CSII alone can lead to lipodystrophy-both lipoatrophy (localized loss of subcutaneous adipose tissue) and LH (abnormal growth of subcutaneous adipose tissue). Lipoatrophy is caused by an adverse immunological response to insulin therapy. ${ }^{29,30}$ It is less common than LH, but can nonetheless be caused by CSII therapy. It should be noted, however, that CSII can also be helpful for treating severe cases of lipoatrophy caused by MDIs. ${ }^{30}$ CGM use is not thought to contribute to lipodystrophy.

Incidence of LH, although still common, ${ }^{14}$ decreased when highly purified insulins came to the market. The mainstay of management remains avoidance of lipohypertrophic areas with careful rotation of CGM and CSII. ${ }^{28}$ Interestingly, recent studies have reported that LH does not appear to adversely affect CSII delivery or CGM sensor accuracy. Karlin et al. reported no difference in infusion set survival or set failure rate due to hyperglycemia between IIS placed in LH and non-LH tissue. ${ }^{3}$ Likewise, DeSalvo et al. placed CGM sensors in $\mathrm{LH}$ and non-LH tissue, and found slightly better accuracy in LH tissue compared to non-LH tissue, indicating that CGM accuracy is not compromised in LH. ${ }^{2}$ Overall, rotating sites still plays a critical role in the prevention (and possible treatment) of $\mathrm{LH}$ and lipoatrophy, but once these conditions develop, there does not appear to be a significant difference in the performance of CSII therapy or CGM, although more studies are needed in this area.

\section{Literature on Skin Care Solutions}

\section{Skin care with diabetes devices}

There are few resources that detail practical recommendations for optimal skin management with diabetes devices. ${ }^{16,18,31}$ The earliest publication on practical CGM use (including dermatological issues) came from an academic children's diabetes center, which described their "toolbox of tapes" to handle poor adhesion, sweating, and skin irritation, ${ }^{18}$ many of which are listed below in Tables $1-4$. The authors emphasized the importance of appropriately cleaning the skin and drying it completely before attempting to place CGM sensors, and also described possible uses for overbandages/ films and tackifying agents. Sweating could be mitigated by applying antiperspirant to the skin before insertion.

The DirecNet Study Group educators likewise published practical considerations for CGM adhesion. ${ }^{16}$ Sensors were less likely to be accidentally dislodged if they were placed on a flat plane such as upper buttocks, upper arm, upper abdomen, or upper thigh. A useful list of commercial adhesives, barriers, and wraps were presented, stressing that individuals often required a combination of products. Bandages placed over the entire sensor and transmitter were not recommended due to buildup of moisture and further loosening of adhesive.

The non-peer reviewed "Pink Panther" series of books written for patients with T1D offer similar suggestions for CGM and CSII usage related to taping, placement, and skin care. ${ }^{31}$ Skin preparation suggestions include exfoliation, trimming hair, and removing oil before adhesive placement to maximize adhesion and minimize irritation. Also discussed is the occurrence of Pressure Induced Sensor Attenuation (PISA), or "compression lows." PISA refers to artificially low sensor glucose readings that occur when sensors abut muscle tissue. This is common with sleeping, laying, or sitting on a sensor, and can be resolved with strategic placement and changing positions.

\section{Skin care in general literature}

Important guidance related to skin care also come from the nursing literature, specifically wound care. It has been clearly shown that medical grade adhesive use can lead to preventable skin irritation concerns when used incorrectly. ${ }^{32,33}$ Examples of incorrect use include selecting tapes with excessive adhesive properties (causing skin injury upon removal), improper application of adhesives, applying to wet/moist skin, not allowing skin preps or barriers to dry (causing irritant contact dermatitis), excessive use of tackifiers/bonding agents, leaving occlusive dressings on too long, not trimming hair under adhesive dressings, removing dressings too quickly or from a high angle, and repeated taping in the same area. ${ }^{33}$ Although these examples are related to generic wound care, they can all be directly applied to clinical diabetes care.

An expert panel of 23 wound care nurses and specialists published recommendations for maintaining optimal skin integrity with medical adhesives. ${ }^{33}$ First step is proper assessment: Skin should be routinely assessed for evidence of damage with every adhesive change. A medical history of allergies/sensitivities should be obtained to minimize risk of reaction to medical adhesive. Next step is taking preventative measures: Nutrition, hydration, and topical skin care measures should be used for optimal skin integrity. Strategically placing adhesive can reduce disruptions from joints or skin movement. Appropriate barrier/adhesive products should be selected based on minimal amount of product necessary, breathability, and gentleness of product. Carefully remove adhesives by including use of removal agents and techniques to minimize tissue damage. The final step is infection prevention: Monitoring sites for pain, edema, erythema, warmth, or suppuration. Nonsterile adhesive products should be stored in closed containers with minimal handling.

\section{Practical comprehensive guidance for skin care with diabetes devices}

The following summary and comprehensive tables present the collective experience of our academic center's adult and pediatric diabetes educators and endocrinologists related to use of diabetes devices. In addition to our extensive experience addressing skin integrity with CSII and CGM, recommendations from the academic literature are incorporated as well. ${ }^{16,18,31-33}$ As additional perspective, contributions from the lay diabetes community have been considered, which incorporate harmoniously with existing literature and expert opinion. ${ }^{34,35}$ Recommendations requiring further research or unclear benefit have been noted.

\section{Device placement considerations}

Device placement is the first consideration in anticipating skin issues with use of CGM sensors and IIS for insulin pumps. Common areas for insertion include the upper buttocks, abdomen, upper hip (flank), upper thigh (inner and outer areas), upper arm, and occasionally forearm (Table 1). Regardless of location, when subcutaneous tissue is insufficient, individuals may feel persistent discomfort when the cannula/sensor abuts underlying musculature. Furthermore, 
compression on the tissue may cause PISA in CGM users. PISA can occur and resolve quickly when pressure is applied and then released from tissue, often leading to characteristic "stalactite" sensor tracings with a precipitous drop in CGM values followed by an abrupt climb back to baseline.

Diabetes providers should elicit a thorough history of known or suspected allergies, as well as any previous history of contact dermatitis before recommending use and type of IIS or CGM. ${ }^{33}$ Skin should be visually inspected for color, texture, previous lesions, and scarring to determine appropriateness for device insertion and adhesive mount. Identifying multiple sites for device insertion allows the wearer to rotate insertion sites, maximizing time for skin to heal inbetween insertions.

Table 1 contains general considerations for device placement as well as specific considerations for commonly used device locations.

\section{Skin care prophylaxis}

Once an appropriate location has been identified, a variety of techniques and barrier agents may be used to minimize risk of hypersensitivity reactions and irritant contact dermatitis (Table 2). Good skin care practices such as thorough cleansing, gentle exfoliation (if needed), and omitting oil containing moisturizer on the candidate area are essential.

A common solution to previously known hypersensitivity reactions has been the off-label use of nasal steroid sprays (e.g., fluticasone) being applied topically to the skin. Although there are no studies about long-term use of nasal steroids applied topically, it has been anecdotally endorsed as a way to prolong sensor use and protect skin from adverse reactions. ${ }^{31,35}$ Many of our clinical patients use this technique, prompting ongoing surveillance by diabetes care providers to assess the skin for changes. Although topical antihistamines have also been suggested as a prophylactic agent, we typically discourage use due to possible local and systemic adverse effects. $^{37}$

For some individuals, liquid barriers may offer sufficient protection from adhesive agents. Solid barrier bandages are a more robust solution for blocking adhesive tapes from contacting skin. Solid barriers can be used in conjunction with liquid barriers or used alone. Many of the products listed in Table 2 provide a combination of barrier protection and adhesive enhancement, maximizing potential device use.

\section{Adhesives and tackifiers}

Enhancing adhesion is important for a variety of device wearers, especially children (due to curvy surfaces and high activity levels), swimmers, individuals who live in high humidity, and athletes (due to increased perspiration and movement). Similar to barrier methods, adhesive agents and tackifiers come in both liquid and solid forms (Table 3).

Adhesive patches or supplemental tapes are usually applied over the CGM/IIS adhesive patch and are used to maintain adhesion throughout device life. The two primary types of adhesive patches are the transparent hypoallergenic films (also used as barrier film above) and kinesiology tapelike products. These come in a variety of precut sizes and shapes, as well as rolls for custom cutting. Adhesive tapes can be used to reinforce tape that is prematurely peeling (Table 3).

\section{Removal techniques and agents}

Careful removal techniques can greatly reduce the likelihood of contact dermatitis and mechanical injury from device use . In general, adhesive tapes should be removed slowly and with low energy, reducing risk of injury. McNichol et al. recommends several excellent approaches that have been incorporated into Table $4 .^{33}$ Diabetes providers can educate individuals about the importance of "low and slow" removals to preserve long-term skin health.

There are a variety of removal aids on the market, which are especially useful when tackifying agents and tapes, that have been used (Table 4). Overall, it is important that the skin is cleansed thoroughly after device removal, as these agents leave oily (and often unpleasantly scented) residues.

\section{Promoting healing}

After device removal, skin should be gently cleansed and assessed for mechanical injury or contact dermatitis (Table 4). If skin is intact and not bothersome, moisturizing lotion may be applied to sooth and protect skin. If skin is intact but irritated, additional anti-inflammatory or antiitch compounds may be applied to the skin. Skin that is broken but not obviously infected can be treated with overthe-counter antimicrobial agents, topical corticosteroids, or liquid antacid to address pain and itching. However, broken skin should be frequently monitored for development of infection. Diabetes providers can educate individuals to assess the skin for worsening of pain and itching, spreading redness, heat, pus, formation of pustules, or a burning sensation. If infection is suspected, individuals should contact their diabetes provider for assessment and prescription of antibiotics if needed. Ongoing monitoring and careful skin care postdevice use can preserve skin for future use.

\section{Antigen avoidance}

Generally, when managing contact dermatitis, avoidance of the offending antigen or agent is the mainstay of the therapy. In the case of allergy to materials in a CGM or IIS, this can be challenging. First and foremost, one must identify the sensitized antigen. This is typically done with the aid of a dermatologist via patch testing. ${ }^{23,33}$ Once the agent has been identified, it can only be avoided if patients are able to determine where it is present. Greater transparency from manufacturers, stating known antigens in the sensors or infusion sets (either on packaging or online), could help in this regard. Additional benefit would be seen if various products offered a variety of adhesives, which may allow patients to avoid a certain antigen without changing device brand. While cross-reactions between similar antigens may still be possible, removing the initial offending agent as early as possible should help to decrease this risk.

\section{Conclusion}

As diabetes technologies evolve to use long-lasting skinadhered components, skin integrity must to be prioritized by the medical diabetes community as never before. Partnerships between academia, industry, diabetes specialists, dermatologists, regulatory agencies, and the influential diabetes community must bring forth better solutions for this very real and 
General considerations

- Assess skin in candidate area: Avoid broken skin, unhealed irritation, and close proximity to another infusion set/sensor (1-2 inches)

- Previous insertion sites should be given a minimum of 1 week to heal before new tape/adhesive agents are placed over sites

- Rotate through multiple sites for preservation of long-term skin integrity ${ }^{32,38}$ (ideally 6-10 placement sites)

- Angled CGM sensors and IIS provide more flexibility with placement in leaner areas on the body due to the depth of insertion

- Although lipohypertrophy may worsen with persistent use of CSII, lipohypertrophic tissue will likely not adversely affect pump or sensor performance ${ }^{2,3}$

- Consider volume of subcutaneous tissue as well as underlying musculature and collagen, ${ }^{33}$ sleep position (e.g., back vs. side sleeper), sports/sports equipment, activity, and clothing preferences

- Place IIS with tubing oriented strategically (e.g., if placed on arm, position tubing origin toward the axilla so tubing can be threaded under clothes; if placed on buttock, position tubing origin upwards to allow for easy disconnection)

- Some individuals may have a strong preference for discrete placement (e.g., not on arms where it might be more visible to others) ${ }^{16}$

\begin{tabular}{|c|c|c|}
\hline Location & Advantages & Professional tips \\
\hline $\begin{array}{l}\text { Upper } \\
\text { buttocks }\end{array}$ & $\begin{array}{l}\text {-FDA approved area for CGM and IIS } \\
\text { insertion } \\
\text { - Relatively flat surface for children, not likely } \\
\text { to crease } \\
\text { Children should be toilet trained before } \\
\text { using } \\
\text { - Good for side sleepers } \\
\text { - Good option for lean children }\end{array}$ & $\begin{array}{l}\text {-Avoid waistline/pantline to prevent discomfort, } \\
\text { irritation, or unintended removal } \\
\text { - Place tape footprint or tubing horizontally to follow } \\
\text { contour of gluteal muscles and minimize dislodging } \\
\text { with clothing changes } \\
\text { - May cause PISA in lean individuals or back sleepers } \\
\text { - Steel cannulas may pop out with gluteus flexion } \\
\text { - Difficult for self-insertion }\end{array}$ \\
\hline Abdomen & $\begin{array}{l}\text {-FDA approved area for CGM and IIS } \\
\text { insertion } \\
\text { - Large surface, with possible sites below and } \\
\text { above umbilicus }\end{array}$ & $\begin{array}{l}\text {-Avoid placement in areas where skin creases } \\
\text { (e.g., hunch over to see where skin folds and } \\
\text { avoid these areas) } \\
\text {-For lean individuals, placement may be better while } \\
\text { sitting/hunching } \\
\text { - Insert 1-2 inches away from umbilicus } \\
\text {-Angled cannula may allow for placement in leaner } \\
\text { abdominal tissue } \\
\text { - If too lean, cannula/sensor may abut muscle causing } \\
\text { discomfort or PISA (CGM) } \\
\text { - Sensitive skin more vulnerable to injury by } \\
\text { mechanical injury }\end{array}$ \\
\hline Upper hip & $\begin{array}{l}\text {-Above pantline, less likely to catch on clothes } \\
\text {-May be a good choice if other areas too lean } \\
\text { (must be able to pinch tissue) }\end{array}$ & $\begin{array}{l}\text { - Possible sites may extend from side of body to } \\
\text { middle of back } \\
\text { - Stay away from pantline to prevent discomfort or } \\
\text { irritation (placement too low) } \\
\text { - Place tape footprint or tubing horizontally, away } \\
\text { from the midline, to minimize dislodging with } \\
\text { clothing changes } \\
\text { - Can cause discomfort if placed along a clothing or } \\
\text { sports equipment line } \\
\text { - May dislodge more easily with sports }\end{array}$ \\
\hline Upper thigh & $\begin{array}{l}\text {-Discrete, concealed under clothes } \\
\text { —Relatively flat surface }\end{array}$ & $\begin{array}{l}\text { - High variability with individual tolerance and } \\
\text { subcutaneous volume } \\
\text { - If too lean, cannula/sensor may hit muscle causing } \\
\text { discomfort or PISA (CGM). Less likely to hit } \\
\text { muscle if placed on outer or inner thigh compared } \\
\text { to front } \\
\text { - May chafe more on inner thigh } \\
\text { - Place pump tubing origin toward torso for ease of } \\
\text { tubing placement }^{\mathrm{b}}\end{array}$ \\
\hline Upper arm & $\begin{array}{l}\text { - Good adhesion for longer footprint of sensors } \\
\text { — Good for back/front sleepers } \\
\text { - Good option for CGM in lean children using } \\
\text { buttock exclusively for IIS } \\
\text { - Comparable CGM accuracy to buttocks and } \\
\text { abdomen }^{36}\end{array}$ & $\begin{array}{l}\text { - Avoid placement too close to axilla which risks skin } \\
\text { irritation with taping } \\
\text {-For CSII, position tubing origin toward axilla so } \\
\text { tubing can be threaded through sleeve of clothing } \\
\text { - Less discrete, visible to others with short sleeves }{ }^{\mathrm{a}} \\
\text { - If too lean, cannula/sensor may hit muscle causing } \\
\text { discomfort or PISA (CGM) }\end{array}$ \\
\hline
\end{tabular}


TABLe 1. (Continued)

\begin{tabular}{|c|c|c|}
\hline Location & Advantages & Professional tips \\
\hline Forearm & $\begin{array}{l}\text {-Easier for self-insertion than upper arm } \\
\text { - Occasionally used for sensor insertions, un- } \\
\text { known if people use for IIS }\end{array}$ & $\begin{array}{l}\text { - Alternative site to add to rotation if primary sites } \\
\text { have damaged skin or other insertions }{ }^{\mathrm{b}} \\
\text { - High variability with individual tolerance and sub- } \\
\text { cutaneous volume } \\
\text { - Not recommended by our center, but is occasionally } \\
\text { used for CGM } \text { CG }^{\mathrm{b}}\end{array}$ \\
\hline
\end{tabular}

Recommendations based on literature (cited), expert opinion, manufacturer's indication, or common clinical practice unless otherwise indicated.

${ }^{\mathrm{a} U}$ Used within our institution or support in public commentary, online articles, diabetes blogs, and social media.

${ }^{\mathrm{b}}$ Unclear support, requires additional studies.

CGM, continuous glucose monitor; CSII, continuous subcutaneous insulin infusion; IIS, insulin infusion sets.

TABle 2. Skin Protection AND Barriers

General consideration

- Clean skin with oil-free, antimicrobial soap and dry thoroughly ${ }^{18,31}$

- Gentle exfoliation recommended for oily skin $^{31}$

- Trim hair with dry razor if needed ${ }^{3}$

- Alcohol may or may not be used, depending on how it is tolerated on skin. May be more important for infection prevention with infusion cannulas than with CGM sensors ${ }^{3}$

- Do not place immediately after a shower/bath or in a steamy bathroom-minimize humidity with hairdryer or application in a dry environment ${ }^{31}$

- Solid or spray antiperspirant (unscented) may help with skin prone to sweating. Apply thin layer, wait 10-15 min, wipe off excess and prepare site ${ }^{18,31,38}$

- What works best for one patient may not work best for another. Patients may need to try several different products Prophylaxis

- Topical prophylactic treatment of skin is generally off-label and has unknown risks associated with long-term use ${ }^{\mathrm{a}}$

\begin{tabular}{lll}
\hline Product & \multicolumn{1}{c}{ Advantages } & \multicolumn{1}{c}{ Professional tips } \\
\hline $\begin{array}{c}\text { Nasal steroid applied topically } \\
\text { (fluticasone, etc.) }\end{array}$ & $\begin{array}{l}\text {-Over the counter } \\
\text { - May reduce hypersensitivity } \\
\text { reaction }\end{array}$ & $\begin{array}{l}\text {-Anecdotally, 1-2 puffs to the skin, } \\
\text { let dry completely before inserting cannula/CGM }\end{array}$ \\
- Unknown consequences with chronic use
\end{tabular}

Skin protection barrier films

- Barrier films may help prevent mild skin irritation from adhesives ${ }^{33}$

- Glucose sensor manufacturers recommend not inserting a sensor through barrier films, ${ }^{38}$ although anecdotal evidence suggests this is commonly done ${ }^{\mathrm{a}}$. Patient may leave a small circle on skin without film for CGM/IIS insertion ${ }^{31}$

- Wipe on skin and let dry completely before placing CGM/IIS. ${ }^{31,33}$

- May apply 1 layer or a second later after first layer has dried

\begin{tabular}{lll}
\hline Product & \multicolumn{1}{c}{ Advantages } & \multicolumn{1}{c}{ Professional tips } \\
\hline IV Prep (Smith\&Nephew) & - Waterproof, breathable barrier film & - Wipes \\
& - Also contains alcohol for antiseptic & - Let dry completely on skin \\
properties & - Although not marketed as having tackifying \\
properties, may see mild enhancement to adhesion
\end{tabular}


TABle 2. (CONTINUED)

\begin{tabular}{|c|c|c|}
\hline Product & Advantages & Professional tips \\
\hline \multicolumn{3}{|c|}{$\begin{array}{l}\text { Barrier Patches and Bandages } \\
\text { - As a barrier, patches/bandages must be placed underneath the sensor/pump tape }{ }^{16,18,31} \\
\text { - Good for placing on skin before sensor adhesive. Recommended to punch hole in it for sensor/cannula, }{ }^{31} \text { however, } \\
\text { many patients report inserting through without problems }{ }^{\mathrm{a}} \\
\text { - Offers more protection from allergy/irritation than liquid barrier wipes }{ }^{\mathrm{a}}\end{array}$} \\
\hline Product & Advantc & Prof \\
\hline $\begin{array}{l}\text { IV3000 } \\
\quad \text { (Smith\&Nephew) }\end{array}$ & $\begin{array}{l}\text { - Transparent, thin film, precut patch } \\
\text {-May be less irritating than sensor/ } \\
\text { cannula adhesives }\end{array}$ & $\begin{array}{l}\text { - May also be used as an adhesive enhancer (see Table 3) } \\
\text { when placed over sensor/infusion set tape } \\
\text {-More prone to peel with water, sweating, humidity } \\
\text {-Many patients report less skin reaction with } \\
\text { IV3000 compared with Tegaderm }\end{array}$ \\
\hline $\begin{array}{l}\text { Tegaderm or } \\
\text { Tegaderm HP }\end{array}$ & -Transparent, thin film, precut patch & $\begin{array}{l}\text { - HP stands for "Holding Power" and may adhere } \\
\text { more strongly than standard Tegaderm } \\
\text {-May also be used as an adhesive enhancer } \\
\text { (Table 3) when placed over sensor/infusion set tape } \\
\text { - More prone to peel with water, sweating, humidity }\end{array}$ \\
\hline $\begin{array}{l}\text { Opsite/Flexifit } \\
\text { (Smith\&Nephew) }\end{array}$ & $\begin{array}{l}\text { - Roll of thin transparent film can } \\
\text { be cut to size }\end{array}$ & $\begin{array}{l}\text { - May also be used as an adhesive enhancer (see Table 3) } \\
\text { when placed under sensor/infusion set tape }\end{array}$ \\
\hline \multirow{4}{*}{$\begin{array}{l}\text { Hydrocolloid dressings: } \\
\text {-DuoDERM } \\
\text { - Toughpads } \\
\text { - (Dynarex) } \\
\text { Dynaderm }^{\mathrm{TM}}\end{array}$} & : - Hydrocolloid provides thick & -More often used under sensors than IIS ${ }^{\mathrm{a}^{1}}$ \\
\hline & $\begin{array}{c}\text { protection } \\
\text {-Waterproof }\end{array}$ & -Offers stronger barrier protection than an adhesive \\
\hline & - Some brands have "extra thin", & $\begin{array}{l}\text { patch, such as } 1 v 3000 \text { or } 1 \text { e } \\
\text { - Recommend cutting hole for }\end{array}$ \\
\hline & $\begin{array}{l}\text { version if desired less thickness } \\
\text { - Some latex free }\end{array}$ & $\begin{array}{l}\text { although patients report inserting sensors through } \\
\text { hydrocolloid dressing without problems }\end{array}$ \\
\hline COMPEED $^{\circledR}$ Plasters & $\begin{array}{l}\text {-Absorbs moisture on skin, } \\
\text { possibly aiding adhesion }\end{array}$ & $\begin{array}{l}\text {-Original intention as blister cushion } \\
\text { - Anecdotally adheres better after warming to skin } \\
\text { temperature in hands before application }{ }^{\mathrm{a}}\end{array}$ \\
\hline
\end{tabular}

Recommendations based on literature (cited), expert opinion, manufacturer's indication, or common clinical practice unless otherwise indicated.

${ }^{\mathrm{a}}$ Used within our institution or support in public commentary, online articles, diabetes blogs, social media.

${ }^{\mathrm{b}}$ Unclear support, requires additional studies.

prevalent concern. Studies are needed to explore prevalence, prevention, and solutions to common skin related issues.

Industry partners/device manufacturers could benefit the diabetes community by conducting or sponsoring more studies of their proprietary adhesive materials over time, and by consulting with dermatology experts to develop new adhesive materials that reduce local reactions. More extensive study of skin issues (root cause and prevention techniques) should be built into phase 2 , phase 3 , and most importantly phase 4 long-term outcomes trials. This is potentially the best source of systematically collected information on long-term exposure to device adhesives. Device companies should further make available the list of chemical components in their adhesives, so patients are better informed about the exposures they encounter with device wear, and can pinpoint potential sources of allergic reaction. This is especially important for long-lasting sensors or large footprint devices (i.e., patch pumps) which maximize on-skin exposure.

From a financial granting agency perspective, grants should be awarded to clinical investigators willing to systematically study ways to preserve skin integrity in both children and adults. These studies should include subjects who have reported previous issues and include multiple combinations of agents/techniques to aid with adhesion and prevention of skin reactions. This may be best achieved with cross-disciplinary partnerships between dermatologists, en- docrinologists, and diabetes educators. Findings from these studies would greatly increase the body of knowledge around skin care and diabetes devices.

Diabetes providers and educators can contribute to the body of knowledge even without conducting large scale trials. Clinicians can provide case studies or write-ups of their experiences using the products and techniques described here or otherwise. Even small scale, single site descriptions of interventions and outcomes provide valuable insight for other diabetes providers trying to provide solutions for their patients. The dearth of peer-reviewed literature in this area makes even small scale investigations highly valuable.

In addition to research and disclosure, there is a need for better surveillance of skin reactions related to using diabetes devices, so agencies such as the Food and Drug Administration can attend to the issue from a regulatory perspective. Patient reporting is a key to understanding the magnitude and nature of the problems related to adhesives. Patients should be encouraged to immediately report all skin concerns to device companies, who may be able to assist in troubleshooting the problem, or assemble internal surveillance information to inform future product design. For severe allergic reactions, patients should also be encouraged to consult with a dermatologist for patch testing and assessment for continued device use. ${ }^{33}$ 
Liquid adhesive agents

- Glucose sensor manufacturers recommend not inserting a sensor through barrier films, ${ }^{38}$ although anecdotal evidence suggests this is commonly done ${ }^{\mathrm{a}}$. May leave a small circle on skin without film for sensor/cannula insertion ${ }^{31}$

- Wipe on skin and let dry completely before placing sensor/IIS.

- May also be soaked into the manufacturer's tape after placement ${ }^{\mathrm{a}}$

- When using prepackaged wipes, tear outer package in half and discard top half. Hold bottom half to avoid touching adhesive

\begin{tabular}{|c|c|c|}
\hline Product & Advantages & Professional tips \\
\hline $\begin{array}{l}\text { Skin Prep/ } \\
\text { No-Sting Skin Prep } \\
\text { (Smith\&Nephew) }\end{array}$ & $\begin{array}{l}\text {-Also provides barrier protection for } \\
\text { skin (Table 2) }\end{array}$ & $\begin{array}{l}\text { —Wipes or liquid } \\
\text { — Not as strong adhesive properties } \\
\text { as Skin Tac or Mastisol }\end{array}$ \\
\hline Skin Tac ${ }^{\mathrm{TM}}$ (Torbot) & $\begin{array}{l}\text {-Additionally provides barrier protection for skin } \\
\text { - Higher adhesive properties than skin prep } \\
\text {-Latex-free, hypoallergenic, nonrubber adhesive }\end{array}$ & $\begin{array}{l}\text { - Wipes or liquid } \\
\text { - Reciprocal removal product called } \\
\text { Tac Away } \\
\text { - May cause irritation for sensitive skin }{ }^{\mathrm{T}}\end{array}$ \\
\hline $\begin{array}{l}\text { Mastisol }{ }^{\circledR} \text { Liquid } \\
\text { Adhesive (Eloquest) }\end{array}$ & $\begin{array}{l}\text { - Higher adhesive properties than Skin } \\
\text { Prep or Skin Tac } \\
\text { - Can be used when other tackifiers have failed }\end{array}$ & $\begin{array}{l}\text { - Comes in liquid, swabs, or single } \\
\text { use vials } \\
\text { - Has reciprocal removal product } \\
\text { called Detachol }^{\circledR} \\
\text { - More likely to cause irritation in } \\
\text { sensitive skin }{ }^{\text {a }} \\
\text { - Has been shown to cause allergic } \\
\text { contact dermatitis in some individuals }\end{array}$ \\
\hline
\end{tabular}

Adhesive Patches or tapes

- As additional adhesive, patches, and tape should be applied over CGM/IIS tape ${ }^{16,31,38}$

- Can cut hole to fit over transmitters or a " $\mathrm{C}$ " shape to fit around IIS tubing disconnection point to reinforce existing tape

- Can cut into strips to use "picture frame" technique around sensor or pump set adhesive ${ }^{18,31}$

- Can be used to reinforce peeling as needed through CGM/IIS life

- Not recommended to cover large or bulky devices (e.g., Dexcom transmitter or patch pump) ${ }^{\mathrm{a}}$

Product Advantages Professional tips

IV3000 (Smith\&Nephew) - Thin transparent film similar to Opsite but not recommended for open wounds -May cause less reactions than Tegaderm ${ }^{\mathrm{a}}$

Tegaderm HP

$\operatorname{Hypafix}^{\circledR}$

psite ${ }^{\mathrm{TM}} /$ Opsite Flexifit ${ }^{\mathrm{TM}}$ (Smith\&Nephew)

Blenderm $^{\mathrm{TM}}(3 \mathrm{M})$

Transpore ${ }^{\mathrm{TM}}$ Surgical Tape

Kinesiology tape

-RockTape ${ }^{\circledR}$

-KT Tape)

Cloth-like adhesive patches specific for diabetes devices:

- GrifGrips ${ }^{\circledR}$

-RockaDex

-Simpatch ${ }^{\mathrm{TM}}$

-HP stands for "Holding Power" and may adhere more strongly than standard Tegaderm

-Thicker, fabric like adhesive than transparent films

- Can be cut to size

—Excellent adhesion for swimming, water

-Breathable transparent film with moderate permeability, can be used for open wounds (in contrast to IV3000)

- clear plastic hypoallergenic tape

— clear, porous, plastic hypoallergenic tape

-Comes in role for custom cutting

-Gentle on skin with mild stretch properties

-Precut for CGM and infusion sets

-Flexible and breathable

-Excellent adhesion for swimming, water

-Bright colors and shapes for children
-May also be used as a barrier (see Table 2) when placed under sensor/infusion set tape - Not breathable, may peel with sweating or if water gets under

- May cause more irritation than IV3000

-Not breathable, may peel with sweating or if water gets under
- Comes as a roll and can be cut to size.

-Excellent staying power and thickness for reinforcing peeling tape ${ }^{\mathrm{a}}$

-May cause less trauma to skin upon removal $^{16}$

- Can come as precut patches or roll

-Tape roll, best used as supplement to peeling tape

-Tape roll, best used as supplement to peeling tape

- Similar material to RockaDex and GrifGrips, in tape role for custom cutting

-Bright colors or neutral tones available

- Similar materials to kinesiology tapes and may be stretched or cut to fit a variety of devices and body shapes 


\begin{tabular}{|c|c|c|}
\hline Product & Advantages & Professional tips \\
\hline $\begin{array}{l}\text { Nonadhesive wraps: } \\
\text {-Coban } \\
\text {-Ace } \\
\text {-Bands4Life }\end{array}$ & $\begin{array}{l}\text {-if unable to tolerate additional adhesive, } \\
\text { wraps may help keep sites in place }\end{array}$ & $\begin{array}{l}\text {-Do not compress skin with elastic wraps. } \\
\text { Wrap loosely and remove during nighttime } \\
\text { to avoid excessive tissue compression }{ }^{\mathrm{a}} \\
\text { - Consider for short-term use-during } \\
\text { sports, activity, etc. }\end{array}$ \\
\hline
\end{tabular}

Recommendations based on literature (cited), expert opinion, manufacturer's indication, or common clinical practice unless otherwise indicated.

${ }^{\mathrm{a}}$ Used within our institution or support in public commentary, online articles, diabetes blogs, social media.

${ }^{\mathrm{b}}$ Unclear support, requires additional studies.

Table 4. Removal Techniques and Agents

General considerations (heavily adapted from McNichol et al. ${ }^{33}$ )

- Loosen edge of adhesive with fingernail and use products listed below if necessary ${ }^{31,33}$

- While removing tapes, use fingers of opposite hand to push skin down and away from adhesive. Continue to move fingers on skin toward adhesive as it is removed ${ }^{33}$

- "Fold back" technique: Remove adhesive slowly, at low angle, folding back on itself ${ }^{33}$

- "Stretch and relax" technique: Films that stretch (e.g., IV3000 or Tegaderm) may be stretched horizontally away from the center (opposite of the fold back technique) while walking fingers under the dressing to continue stretching it ${ }^{33}$

- Use adhesive removal wipes to rub the skin under the tape toward the adhesive as it is removed. This helps loosen adhesive from skin and reduce pain with removal ${ }^{31}$

Removal aids

- When using prepackaged wipes, tear outer package in half and discard top half. Hold bottom half to avoid touching adhesive remover

- All products leave oily residue: Wash area thoroughly with soap, rinse, and dry before attempting new insertion/adhesive in area

Product

Description

Uni-solve Adhesive Remover (Smith\&Nephew)

-AllKare Adhesive Removal Wipe (ConvaTec Inc)

Tac Away Adhesive Removal Wipes (Torbot)

Detachol Adhesive Remover (Eloquest)

Household oils ${ }^{\mathrm{a}}$ :

- Baby oil

- Coconut oil

-Olive oil

Healing

- Assess for hypersensitivity reaction or contact dermatitis

- If skin is intact, healing strategies include anti-inflammatory and anti-itch agents

- If skin integrity is broken, strategies may include antimicrobial agents, liquid antacids, seeking medical care

\begin{tabular}{|c|c|c|}
\hline Product & Advantages & Professional tips \\
\hline Benadryl & -Inexpensive & $\begin{array}{l}\text {-Histamine blocker to relieve itching } \\
\text { - Use as directed }\end{array}$ \\
\hline Hydrocortisone & $\begin{array}{l}\text {-Inexpensive } \\
\text {-Anti-inflammatory and anti-itch } \\
\text { properties }\end{array}$ & $\begin{array}{l}\text { - Paste or ointment to relieve pain and inflammation } \\
\text { - Apply thin layer to irritated skin once or twice per day as } \\
\text { needed and per manufacturer instructions } \\
\text { - Prolonged use not recommended due to potential local and } \\
\text { systemic adverse effects }{ }^{41, b}\end{array}$ \\
\hline $\begin{array}{l}\text { Liquid Antacid } \\
\text { (Maalox) }\end{array}$ & $\begin{array}{l}\text {-Inexpensive } \\
\text {-Gentle on open skin and painful } \\
\text { irritation }\end{array}$ & $\begin{array}{l}\text { - Liquid to relieve pain and inflammation } \\
\text { - Dab on broken inflamed skin and let dry into chalky paste } \\
\text { - May stain/rub off on clothes }\end{array}$ \\
\hline Polysporin/Bacitracin & $\begin{array}{l}\text {-Over the counter } \\
\text { - Reduces risk of infection with } \\
\text { broken skin }\end{array}$ & $\begin{array}{l}\text { - Use as directed to reduce chance of skin infection } \\
\text { - If signs of infection worsen, advice patients to call diabetes } \\
\text { provider immediately }\end{array}$ \\
\hline
\end{tabular}

Recommendations based on literature (cited), expert opinion, manufacturer's indication, or common clinical practice unless otherwise indicated.

${ }^{\mathrm{a}}$ Used within our institution or support in public commentary, online articles, diabetes blogs, social media.

${ }^{\mathrm{b}}$ Unclear support, requires additional studies. 
Diabetes clinicians play a paramount role in improving skin care for patients with diabetes, and they can increase likelihood of device success. Providers and diabetes educators can use the information herein to aid with optimal device placement, skin protection, adhesive enhancers, and promotion of healing. Clinical investigations should continue to elucidate key practices for promoting skin health and prolonging use of diabetes devices with the goal of improving glycemic control and quality of life for people with diabetes.

\section{Acknowledgments}

Part of this work was funded by time from an NIH K12 award (NIDDK 2K12DK094712-06). We thank all the providers, patients, and families at the Barbara Davis Center, whose experiences with diabetes contributed to this article.

\section{Author Disclosure Statement}

L.H.M. is a contract product trainer for Medtronic Diabetes and has received speaking honoraria from Insulet Corporation and Tandem Diabetes Care. C.B. is a contract product trainer for Medtronic Diabetes. S.P. conducts research supported by Dexcom, Inc, Eli Lilly, and the NIDDK, and provides consulting services for the JAEB Center. G.P.F. conducts research supported by Medtronic, Tandem, Insulet, Bigfoot, Beta Bionics, Abbott, and Dexcom and has been a paid speaker and advisory board member for Dexcom and Tandem.

\section{References}

1. American Diabetes Association: Standards of medical care in diabetes-2017. Diabetes Care 2017;40(Supplement 1): S64.

2. DeSalvo DJ, Maahs DM, Messer L, et al.: Effect of lipohypertrophy on accuracy of continuous glucose monitoring in patients with type 1 diabetes. Diabetes Care 2015;38: e166-e167.

3. Karlin AW, Ly TT, Pyle L, et al.: Duration of infusion set survival in lipohypertrophy versus nonlipohypertrophied tissue in patients with type 1 diabetes. Diabetes Technol Ther 2016;18:429-435.

4. Miller KM, Foster NC, Beck RW, et al.: Current state of type 1 diabetes treatment in the U.S.: updated data from the T1D Exchange clinic registry. Diabetes Care 2015;38:971978.

5. Sherr JL, Hermann JM, Campbell F, et al.: Use of insulin pump therapy in children and adolescents with type $1 \mathrm{di}-$ abetes and its impact on metabolic control: comparison of results from three large, transatlantic paediatric registries. Diabetologia 2016;59:87-91.

6. Tanenbaum ML, Hanes SJ, Miller KM, et al.: Diabetes device use in adults with type 1 diabetes: barriers to uptake and potential intervention targets. Diabetes Care 2017;40: 181-187.

7. Forlenza GP, Argento NB, Laffel LM: Practical considerations on the use of continuous glucose monitoring in pediatrics and older adults and nonadjunctive use. Diabetes Technol Ther 2017;19(S3):S13-S20.

8. Olafsdottir AF, Attvall S, Sandgren U, et al.: A clinical trial of the accuracy and treatment experience of the flash glucose monitor FreeStyle libre in adults with type 1 diabetes. Diabetes Technol Ther 2017;19:164-172.
9. Laffel LM, Aleppo G, Buckingham BA, et al.: A practical approach to using trend arrows on the Dexcom G5 CGM system to manage children and adolescents with diabetes. J Endocr Soc 2017;1:1461-1476.

10. Heinemann L, Kamann S: Adhesives used for diabetes medical devices: a neglected risk with serious consequences? J Diabetes Sci Technol 2016;10:1211-1215.

11. Berg AK, Olsen BS, Thyssen JP, et al.: High frequencies of dermatological complications in children using insulin pumps or sensors. Pediatr Diabetes 2018;19:733-740.

12. Conwell LS, Pope E, Artiles AM, et al.: Dermatological complications of continuous subcutaneous insulin infusion in children and adolescents. J Pediatr 2008;152:622628.

13. Binder E, Lange O, Edlinger M, et al.: Frequency of dermatological side effects of continuous subcutaneous insulin infusion in children and adolescents with type 1 diabetes. Exp Clin Endocrinol Diabetes 2015;123:260-264.

14. Pickup JC, Yemane N, Brackenridge A, Pender S: Nonmetabolic complications of continuous subcutaneous insulin infusion: a patient survey. Diabetes Technol Ther 2014; 16:145-149.

15. Jadviscokova T, Fajkusova Z, Pallayova M, et al.: Occurence of adverse events due to continuous glucose monitoring. Biomed Pap Med Fac Univ Palacky Olomouc Czech Repub 2007;151:263-266.

16. Englert K, Ruedy K, Coffey J, et al.: Skin and adhesive issues with continuous glucose monitors: a sticky situation. J Diabetes Sci Technol 2014;8:745-751.

17. Messer L, Ruedy K, Xing D, et al.: Educating families on real time continuous glucose monitoring: the DirecNet navigator pilot study experience. Diabetes Educ 2009;35:124-135.

18. Ives B, Sikes K, Urban A, et al.: Practical aspects of realtime continuous glucose monitors: the experience of the Yale Children's Diabetes Program. Diabetes Educ 2010;36: 53-62.

19. Feig DS, Donovan LE, Corcoy R, et al.: Continuous glucose monitoring in pregnant women with type 1 diabetes (CONCEPTT): a multicentre international randomised controlled trial. Lancet 2017;390:2347-2359.

20. Schwensen JF, Friis UF, Zachariae C, Johansen JD: Sensitization to cyanoacrylates caused by prolonged exposure to a glucose sensor set in a diabetic child. Contact Dermatitis 2016;74:124-125.

21. Bolinder J, Antuna R, Geelhoed-Duijvestijn P, et al.: Novel glucose-sensing technology and hypoglycaemia in type 1 diabetes: a multicentre, non-masked, randomised controlled trial. Lancet 2016;388:2254-2263.

22. Brahimi N, Potier L, Mohammedi K: Cutaneous adverse events related to FreeStyle Libre device. Lancet 2017;389: 1396.

23. Herman A, Aerts O, Baeck M, et al.: Allergic contact dermatitis caused by isobornyl acrylate in Freestyle(R) Libre, a newly introduced glucose sensor. Contact Dermatitis 2017;77:367-373.

24. Bolinder J, Antuna R, Geelhoed-Duijvestijn P, et al.: Cutaneous adverse events related to FreeStyle Libre deviceAuthors' reply. Lancet 2017;389:1396-1397.

25. Janeway CAJ, Travers P, Walport M: Hypersensitivity diseases. Immunobiology: The Immune System in Health and Disease. 5th ed. New York: Garland Science, 2001.

26. Ale IS, Maibacht HA: Diagnostic approach in allergic and irritant contact dermatitis. Expert Rev Clin Immunol 2010; 6:291-310. 
27. Tan CH, Rasool S, Johnston GA: Contact dermatitis: Allergic and irritant. Clin Dermatol 2014;32:116-124.

28. Richardson T, Kerr D: Skin-related complications of insulin therapy: epidemiology and emerging management strategies. Am J Clin Dermatol 2003;4:661-667.

29. Ramos AJ, Farias MA: Human insulin-induced lipoatrophy: a successful treatment with glucocorticoid. Diabetes Care 2006;29:926-927.

30. Radermecker RP, Piérard GE, Scheen AJ: Lipodystrophy reactions to insulin: effects of continuous insulin infusion and new insulin analogs. Am J Clin Dermatol 2007;8:21-28.

31. Chase HP, Messer L: Understanding Insulin Pumps and Continuous Glucose Monitors. 3rd ed. Denver: Children's Diabetes Research Foundation, 2016.

32. Bryant RA: Saving the skin from tape injuries. Am J Nurs 1988;88:189-191.

33. McNichol L, Lund C, Rosen T, Gray M: Medical adhesives and patient safety: State of the science: consensus statements for the assessment, prevention, and treatment of adhesiverelated skin injuries. J Wound Ostomy Continence Nurs 2013;40:365-380; quiz E361-E362.

34. Tsai A: Tips for Tackling Adhesive Irritation and Allergies. Diabetes Forcast. 2017 (March 2017). www.diabetesforecast .org/2017/mar-apr/the-sticking-point.html. (accessed March 1, 2018).

35. Brown A: CGM Tips and Tricks for Better Accuracy and Less Frustration. diaTribe Learn https://diatribe.org/CGMtips. (accessed January 24, 2018).

36. Faccioli S, Del Favero S, Visentin R, et al.: Accuracy of a CGM sensor in pediatric subjects with type 1 diabetes.
Comparison of three insertion sites: arm, abdomen, and gluteus. J Diabetes Sci Technol 2017;11:1147-1154.

37. Eichenfield LF, Tom WL, Berger TG, et al.: Guidelines of care for the management of atopic dermatitis: section 2 . Management and treatment of atopic dermatitis with topical therapies. J Am Acad Dermatol 2014;71:116-132.

38. Medtronic Diabetes: Tape Tips and Site Management. https:// www.medtronicdiabetes.com/sites/default/files/library/down load-library/workbooks/Tape\%20Tips\%20and\%20Site\%20 Management.pdf (accessed January 17, 2018).

39. Meikle A, Vaghadia H, Henderson C: Allergic contact dermatitis at the epidural catheter site due to Mastisol ${ }^{\circledR}$ liquid skin adhesive. Can J Anaesth 2012;59:815-816.

40. http://www.smith-nephew.com/professional/products/ advanced-wound-management/no-sting-skin-prep/. (accessed January 17, 2018).

41. Hengge UR, Ruzicka T, Schwartz RA, Cork MJ: Adverse effects of topical glucocorticosteroids. J Am Acad Dermatol 2006;54:1-15; quiz 16-18.

Address correspondence to: Laurel H. Messer, RN, MPH, CDE Barbara Davis Center for Childhood Diabetes University of Colorado Denver 1775 Aurora CT MS A140 Aurora, CO 80045

E-mail: laurel.messer@ucdenver.edu 